\title{
The relationship between polymorphism of insulin-like growth factor I gene and susceptibility to type 2 diabetes in Uygur population, Xinjiang, China
}

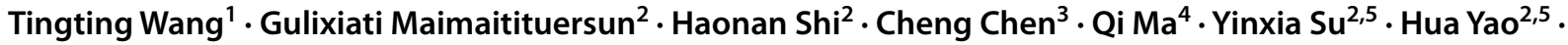 \\ Jia Zhu ${ }^{6}$
}

Received: 11 June 2021 / Accepted: 17 December 2021 / Published online: 30 January 2022

(c) The Author(s) 2021

\begin{abstract}
Background Type 2 diabetes (T2DM) susceptibility varies among different populations and is affected by gene single nucleotide polymorphism (SNP). Insulin-like growth factor (IGF)-1 gene, which has many SNP loci, is involved in T2DM pathogenesis. However, the relationship of $I G F-1$ gene polymorphism with T2DM in Uyghur population is less studied. Objective To investigate the relationship between T2DM susceptibility and polymorphism of IGF-1 gene in Uyghur population of Xinjiang, China.

Methods This study enrolled 220 cases (122 males (55.46\%) and 98 females (44.54\%); mean age of 53.40 \pm 10.94 years) of T2DM patients (T2DM group) and 229 (124 males (54.15\%) and 105 females (45.85\%); mean age of 51.64 \pm 10.48 years) healthy controls (control group). Biochemical indexes were determined. IGF-1 gene polymorphism was analyzed by SNP genotyping.

Results The levels of TG, HDL, LDL, BUN, and Cr were statistically significant between the T2DM group and the control group. In terms of $I G F-1$ polymorphism, T2DM group had higher frequency of AA genotype $(\mathrm{OR}=2.40,95 \% \mathrm{CI}=1.19-$ 4.84) and allele $\mathrm{A}(\mathrm{OR}=1.55,95 \% \mathrm{CI}=1.17-2.06)$ of $\mathrm{rs} 35767$ loci, suggesting that $\mathrm{rs} 35767$ is related to the occurrence of T2DM. A total of 5 gene interaction models was obtained through analyzing the interaction of 5 SNP loci with the GMDR method. Among them, the two-factor model that included rs35767 locus and rs5742694 locus had statistical difference with a large cross-validation consistency (10/10). The combination of GG/CC, GA/AA, AA/AA, and AA/AC genotype was in high-risk group, whereas the combination of GG/AA, GG/AC, GA/AC and GA/CC genotype was in the low-risk group. The risk of T2DM in the high-risk group was 2.165 times than that of the low-risk group $(\mathrm{OR}=2.165,95 \% \mathrm{CI}=1.478-3.171)$. Conclusion TG, HDL, LDL, BUN, and Cr are influencing factors of T2DM in Uyghur population. The rs35767 locus of IGF-1 gene may be associated with T2DM in Uyghur population. The high-risk group composing of rs35767 locus and rs5742694 locus has a higher risk of T2DM.
\end{abstract}

Keywords $I G F-1$ gene $\cdot$ Gene polymorphism - Type 2 diabetes · Uyghur

Tingting Wang, Gulixiati Maimaitituersun, Haonan Shi contribute equally to this work.

\section{Qi Ma \\ 1346510539@qq.com \\ jslzgd@outlook.com}

$\triangle$ Jia Zhu

Extended author information available on the last page of the article

\section{Introduction}

Type 2 diabetes (T2DM) is a chronic metabolic disease with abnormally high blood glucose caused by insufficient insulin secretion or insulin resistance (Ahmed et al. 2020). Like other metabolic diseases, T2DM is affected by both genetic and environmental factors, and is related to the occurrence of many diseases (Sarega et al. 2016). The prevalence of T2DM varies among different populations and regions. For example, it has been shown that the prevalence of T2DM in Uyghur population of Xinjiang, China is $8.16 \%$, and that in Kazakh population is $1.47 \%$ (Tao et al. 2008). Another survey showed 
that the prevalence of T2DM in Xinjiang Uygur population was $9.5 \%$ (Awuti et al. 2012).

It is known that there are 56 ethnic groups in China. The Han nationality is the dominant ethnic group in China and its population accounts for $91.11 \%$ of the total population; while the population of the other 55 ethnic groups accounts for $8.89 \%$. The majority of the Uyghur ethnic group lives in the Xinjiang Uyghur Autonomous Region, mainly in the south of the Tianshan Mountains (including Hotan, Kashgar, and Aksu). According to the seventh national census statistics of China conducted in Xinjiang on 2020, the Uyghur, as the dominant ethnic minority, has a population of 11.6243 million, accounting for $44.96 \%$ of the population in Xinjiang, and, the Han ethnic group has a population of 10.9201 million, accounting for $42.24 \%$. The genetic and environmental factors of T2DM of Han and other ethnic groups have been extensively studied (Hu and Jia 2018; Gong et al. 2019). However, such studies on the Uyghur population in Xinjiang are less reported.

Insulin-like growth factor I (IGF-1) regulates cell proliferation and is essential for mammalian growth and development (Kwasniewski et al. 2015). IGF-1 promotes the uptake of glucose by tissues, stimulates gluconeogenesis and glycolysis through insulin-like effects, thereby promoting protein and fat synthesis and playing an important role in cell proliferation and apoptosis (Mancuso et al. 2017; Yakar et al. 2002). Gene polymorphism, especially single nucleotide polymorphism (SNP), is an important factor affecting the susceptibility and phenotype of T2DM (Bakhashab et al. 2020; Kodama et al. 2018). The $I G F-1$ gene is located on chromosome 12 , with a total length of $84,734 \mathrm{bp}$, and contains 3103 SNP loci (Franco et al. 2014). These polymorphic sites may have different functions due to their different positions, such as regulating gene expression levels, and affecting gene post-transcriptional regulation or amino acid sequence (Qin et al. 2019). For example, it has been reported that the rs35767 and rs5742612 loci of the IGF-1 gene are related to coronary artery damage (Fujita et al. 2012). The rs2162679 and rs6214 loci are correlated with diabetic eye diseases (Hu et al. 2010; Xing et al. 2014). However, the relationship of $I G F-1$ gene polymorphism with T2DM is less studied.

Herein, this study investigates the relationship between IGF-1 gene polymorphism and T2DM in the Uyghur population from Urumqi, Xinjiang. The rs5742694, rs5742612, rs6218, rs35749 and rs35767 SNP of IGF-1 gene was analyzed. Our findings may provide a scientific basis for the prevention and treatment of T2DM.

\section{Materials and methods}

\section{Subjects}

At first, we screened 721 subjects and obtained informed consent from 589 subjects. Among the 589 subjects, 449 patients met the inclusion criteria, including 220 patients with T2DM and 229 control subjects. In detail, the 220 patients with T2DM were hospitalized in the First Affiliated Hospital of Xinjiang Medical University from January to December 2018. They were aged $20-70$ years old. Meanwhile, the 229 controls were age-matched healthy subjects who received physical examination during the same period. None of them had hyperglycemia or hyperuricemia. Inclusion criteria: (1) Uyghur patients lived in Urumqi, Xinjiang; (2) Patients with fasting blood glucose $\geq 7.0 \mathrm{mmol} / \mathrm{L}$ (Yakar et al. 2002) or those who have been diagnosed with T2DM; Exclusion criteria: (1) patients with blood diseases (such as polycythemia, myelodysplasia, multiple myeloma, acute and chronic hemolytic anemia, leukemia, and lymphoma) and other malignant tumors, were excluded; (2) patients with non-gouty kidney stones, kidney failure and other kidney diseases were excluded; (3) patients who had recently taken medications (such as thiazide diuretics, aspirin, and pyrazinamide) that could induce blood uric acid (UA) increase were excluded. The detailed subject recruitment process is shown in Fig. 1. All subjects signed the informed consent. This study was approved by the Ethics Committee of the First Affiliated Hospital of Xinjiang Medical University.

\section{Questionnaire survey and physical examination}

The structured self-designed questionnaires that combined the living habits and ethnic customs of the Xinjiang Uyghur

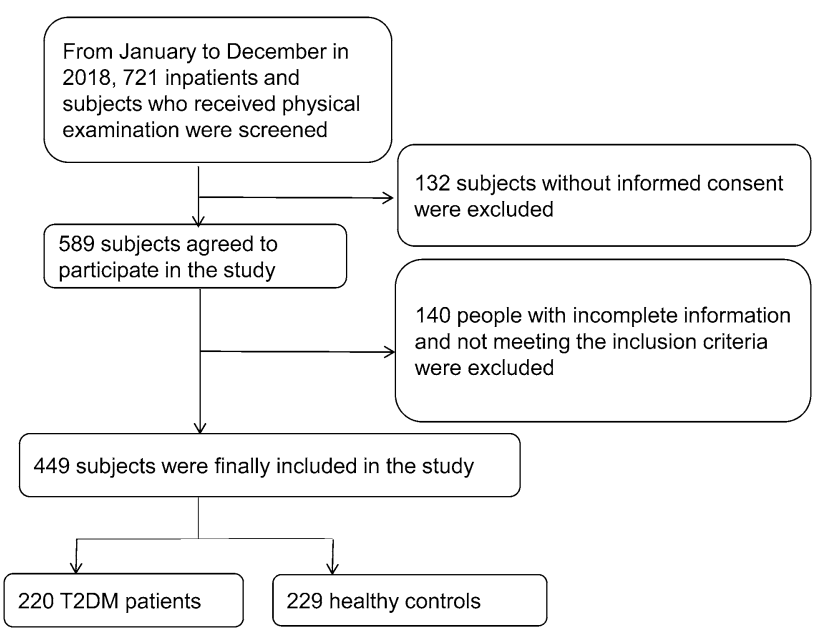

Fig. 1 The detailed subject recruitment process 
population were used. Trained investigators proficient in the Uyghur language conducted one-to-one inquiries and physical examinations to obtain basic information. The survey information included disease history, diet and living habits, and family history, etc.; T2DM information (the course of T2DM, diagnosis age, confirmed blood glucose, highest blood glucose, complications and concomitant diseases); risk factors related to UA; lifestyle (physical exercise, smoking, drinking, tea drinking and diet control after illness, etc.); social and psychological factors, etc.

\section{Determination of biochemical indicators}

Peripheral venous blood $(2 \mathrm{~mL})$ was collected after $12 \mathrm{~h}$ of fasting. Serum was isolated within $2 \mathrm{~h}$. The concentration of UA in serum was determined by the uricase method. Serum levels of triglyceride (TG), total cholesterol (TC), highdensity lipoprotein (HDL), low-density lipoprotein (LDL), urea nitrogen (BUN), and creatinine $(\mathrm{Cr})$ were all measured on the Abbott ARCHITECT CI16000 biochemical analyzer (Genesky Biotechnologies Inc., Shanghai, 201315).

\section{Genotype analysis}

The DNA was extracted from peripheral blood samples using the DNA extraction kit (QIAGEN, Germany). A multiplex PCR-ligase detection reaction method was used for genotyping of five SNPs. For each SNP, the alleles were distinguished by different fluorescent labels of allele specific oligonucleotide probe pairs. Different SNPs were further distinguished by different extended lengths at the 3'-end. Negative quality control, Hardy-Weinberg Equilibrium and Minor Allele Frequency analysis on typing results were then carried out. The primers used in this study are listed in Table 1.

\section{Statistical analysis}

SPSS20.0 software was used for statistical analysis. The count data was expressed as percentage, and the measurement data was expressed as mean $\pm \mathrm{SD}$. The comparison between the two groups was performed by the Chi-Square $\left(\chi^{2}\right)$ test or the rank sum test. The generalized multi-factor dimensionality reduction (GMDR) software was used for the interaction analysis of the SNPs loci of the $I G F-1$ gene, and for selecting the optimal gene interaction model. The MDR software was used to plot on-site interactive radiographs to determine whether the interaction is antagonistic or synergistic. $P \leq 0.05$ indicates that the difference is statistically significant.

\section{Results}

\section{Basic information of subjects}

The basic clinical data of patients is shown in Table 2 . There were 220 cases in the T2DM group, including 122 (55.46\%) males and 98 (44.54\%) females, with an average age of $53.40 \pm 10.94$ years. There were 229 cases in the control group, including 124 males $(54.1 \%)$ and 105 females (45.9\%), with an average age of $51.64 \pm 10.48$ years (Table 2). The gender and age of the T2DM group and the control group were not statistically significant $(P>0.05)$. The comparison of urban and rural residents and educational level between the two groups was statistically significant $(P<0.05)$. Importantly, the levels of TG, HDL, LDL, BUN, and $\mathrm{Cr}$ were statistically significant between the T2DM group and the control group $(P<0.05)$ (Table 3$)$. There were no significant differences in other factors $(P>0.05)$.

\section{Hardy-Weinberg equilibrium test of IGF-1 gene polymorphism in the T2DM group and the control group}

In this study, the Hardy-Weinberg Equilibrium test was also performed on the 5 loci of the IGF-1 gene in the T2DM group and the control group. The results showed that the differences of all loci were not statistically significant $(P>0.05$, Table 4), indicating that these 5 loci have reached a genetic balance in the Uyghur population and have good population representativeness.

\section{Comparison of SNP sites of IGF-1 gene between the T2DM group and the control group}

A comparison of IGF-1 gene polymorphism between the T2DM group and the control group showed that there were no significant differences in rs35749, rs5742612, rs5742694, and rs6218 loci $(P>0.05)$. Compared with the control group, T2DM group had higher frequency of AA genotype $(\mathrm{OR}=2.40,95 \% \mathrm{CI}=1.19-4.84)$ and allele $\mathrm{A}(\mathrm{OR}=1.55$, $95 \% \mathrm{CI}=1.17-2.06)$ of $\mathrm{rs35767}$ loci, suggesting that rs35767 is related to the occurrence of T2DM (Table 5).

\section{Comparison of rs35767 (G/A) polymorphism of IGF-1 gene between the T2DM group and the control group}

The rs35767 genotype (GG, GA, AA), alleles (G, A), dominant model (GA + AA, GG) and recessive model $(\mathrm{AA}, \mathrm{GG}+\mathrm{GA}$ ) of $I G F-1$ gene in the T2DM and the control groups were also compared. The results showed 
Table 1 Primer information for IGF-1 gene genotyping

\begin{tabular}{|c|c|c|c|c|}
\hline SNP & Chromosome position & SNP property & PCR primer & Ligation primer \\
\hline rs5742694 & $102,799,236$ & Intron3 & $\begin{array}{l}\text { rs5742694F: CCTGGCCGTGTTCTGCTT } \\
\text { TC } \\
\text { rs5742694FR: TGCGGGTTTGATCAG } \\
\text { CTACAGA }\end{array}$ & $\begin{array}{l}\text { rs5742694FA: TACGGTTATTCGGGCTCC } \\
\text { TGTCATGGGGCCACAGAATAGCAG } \\
\text { CA } \\
\text { rs5742694FC: TTCCGCGTTCGGACTGAT } \\
\text { ATCATGGGGCCACAGAATAGCAACC } \\
\text { rs5742694FP: CTAATGTTCCCAAACTCC } \\
\text { TTGAAATGTTTTTTT }\end{array}$ \\
\hline rs5742612 & $102,874,864$ & 5'-flanking & $\begin{array}{l}\text { rs5742612_rs2288377F: GGGGGATGG } \\
\text { GAGAGCAATTTTA/rs5742612_- } \\
\text { rs2288377R: GCCTGCCCCTCCATA } \\
\text { GGTTCTA }\end{array}$ & $\begin{array}{l}\text { rs5742612FA: TACGGTTATTCGGGCTCC } \\
\text { TGTCCTTGTCCCAGTTGCCAAGTG } \\
\text { TGA } \\
\text { rs5742612FG: TTCCGCGTTCGGACTGAT } \\
\text { ATCCTTGTCCCAGTTGCCAAGTGTGG } \\
\text { rs5742612FP: GGTGTGATCTCATTTCCT } \\
\text { AGAACCTATGTTTTTTT } \\
\text { rs5742694FA: TACGGTTATTCGGGCTCC } \\
\text { TGTCATGGGGCCACAGAATAGCAG } \\
\text { CA } \\
\text { rs5742694FC: TTCCGCGTTCGGACTGAT } \\
\text { ATCATGGGGCCACAGAATAGCAACC }\end{array}$ \\
\hline rs6218 & $102,793,633$ & 3'-UTR_exon5 & $\begin{array}{l}\text { rs6218F: TTGGGGGATTTTTGACTG } \\
\text { TGGA } \\
\text { rs6218R: CCCTCTGCCTGTTTTCCA } \\
\text { GACA }\end{array}$ & $\begin{array}{l}\text { rs6218RA: TACGGTTATTCGGGCTCC } \\
\text { TGTGGCACTTCTTTTTATTTCTTGTCC } \\
\text { CCTGT } \\
\text { rs6218RG: TTCCGCGTTCGGACTGAT } \\
\text { ATGGCACTTCTTTTTATTTCTTGTCCC } \\
\text { CTGC } \\
\text { rs6218RP: GTGTACCTTTTAAAATTATTC } \\
\text { CCTCTCAACATT }\end{array}$ \\
\hline rs35749 & $102,940,183$ & 5'-flanking & $\begin{array}{l}\text { rs35749F: GGGTTGATATGGGGAGGG } \\
\text { TGTT } \\
\text { rs35749R: GCCCAATGATATGAAAGC } \\
\text { CCAAAT }\end{array}$ & $\begin{array}{l}\text { rs35749RC: TCTCTCGGGTCAATTCGT } \\
\text { CCTTCGATACATGGGTTCTTTCAG } \\
\text { CAAATTGTG } \\
\text { rs35749RP: TCCTATCTTCCTCAGGAA } \\
\text { CTGATAAAGTTCTTTTTT } \\
\text { rs35749RT: TGTTCGTGGGCCGGATTA } \\
\text { GTCGATACATGGGTTCTTTCAGCA } \\
\text { AATTGTA }\end{array}$ \\
\hline rs35767 & $102,875,569$ & 5'-flanking & $\begin{array}{l}\text { rs35767F: GAGCAGACATACCTCTTT } \\
\text { CCCTAGAGAGC } \\
\text { rs35767R: GATTTCAAGCAGAACTGT } \\
\text { GTTTTCAGTTG }\end{array}$ & $\begin{array}{l}\text { rs35767RA: TACGGTTATTCGGGCTCC } \\
\text { TGTTGTCAGTCCCCTGAGAGTCACGT } \\
\text { rs35767RG: TTCCGCGTTCGGACTGAT } \\
\text { ATTGTCAGTCCCCTGAGAGTCACGC } \\
\text { rs35767RP: GGAAAAAACAAAAAAGAA } \\
\text { AAAATTCAAGGTCCAGGTTATTTC } \\
\text { CAC }\end{array}$ \\
\hline
\end{tabular}

Table 2 Basic data of the enrolled subjects

\begin{tabular}{lllll}
\hline Index & T2DM group $(n=22)$ & Control group $(n=229)$ & $\chi^{2} / t$ value & $P$ value \\
\hline Male & $122(55.46 \%)$ & $124(54.15 \%)$ & 0.106 & 0.744 \\
Female & $98(44.54 \%)$ & $105(45.85 \%)$ & & \\
Age & $53.40 \pm 10.94$ & $51.64 \pm 10.48$ & -1.739 & 0.083 \\
Citizens & $111(50.45)$ & $198(86.46 \%)$ & 67.80 & 0.000 \\
Education & & & & \\
$\quad$ College degree and above & $151(68.63 \%)$ & $180(78.60 \%)$ & 15.75 & 0.016 \\
Below college & $69(31.37 \%)$ & $49(21.40 \%)$ & & \\
\hline
\end{tabular}


Table 3 Comparison of biochemical indicators between the T2DM group and control group (mean $\pm \mathrm{SD}$ )

\begin{tabular}{lrrrl}
\hline Index & T2DM group & Control group & \multicolumn{1}{l}{$t / t^{\prime}$} & $P$ value \\
\hline BMI $\left(\mathrm{kg} / \mathrm{m}^{2}\right)$ & $26.50 \pm 3.34$ & $26.91 \pm 4.09$ & 1.195 & 0.233 \\
TG $(\mathrm{mmol} / \mathrm{L})$ & $2.11 \pm 1.32$ & $1.76 \pm 1.41$ & -2.682 & 0.008 \\
TC $(\mathrm{mmol} / \mathrm{L})$ & $4.19 \pm 1.14$ & $4.02 \pm 1.43$ & -1.319 & 0.157 \\
HDL $(\mathrm{mmol} / \mathrm{L})$ & $1.04 \pm 0.56$ & $1.35 \pm 0.55$ & 5.840 & 0.000 \\
LDL $(\mathrm{mmol} / \mathrm{L})$ & $3.03 \pm 1.43$ & $2.54 \pm 1.00$ & -4.158 & 0.000 \\
BUN $(\mathrm{mmol} / \mathrm{L})$ & $4.50 \pm 1.81$ & $4.91 \pm 1.95$ & 2.261 & 0.024 \\
Cr $(\mu \mathrm{mol} / \mathrm{L})$ & $49.81 \pm 24.18$ & $78.06 \pm 20.81$ & 13.492 & 0.000 \\
\hline
\end{tabular}

$B M I$ Body Mass Index, $T G$ Triglyceride, $T C$ Total cholesterol, $H D L$ High density lipoprotein, $L D L$ Low density lipoprotein, $B U N$ Blood urea nitrogen, $\mathrm{Cr}$ Creatinine

that the frequency of dominant model GA + AA in T2DM group was significantly higher than that in control group $(P<0.05)$ (Table 6$)$. GG of rs35767 of $I G F-1$ gene indicated a lower risk of T2DM $(O R=0.665,95 \%$ $\mathrm{CI}=0.458-0.965)$. The frequency of AA in the recessive model of the T2DM group was significantly higher than that of the control group $(P<0.05)$ (Table 6). Type $\mathrm{GG}+\mathrm{GA}$ of rs35767 of $I G F-1$ gene suggested a lower risk of $\mathrm{T} 2 \mathrm{DM}(\mathrm{OR}=0.486,95 \% \mathrm{CI}=0.247-0.957)$. There results suggest that rs35767 is associated with the occurrence of T2DM.

\section{Interaction analysis of IGF-1 gene polymorphism}

The interaction of 5 SNP loci was analyzed by the GMDR method and 5 gene interaction models were generated. Among them, the two-factor model, which contained rs35767 and rs5742694, was the optimal gene interaction model with statistical difference $(P<0.05)$ and a large cross-validation consistency (10/10). We found that the interaction between rs35767 and rs5742694 was highly synergistic (Fig. 2). Furthermore, the combination of GG/ CC, GA/AA, AA/AA, and AA/AC genotype of rs35767 and rs5742694 was in the high-risk group, whereas the combination of GG/AA, GG/AC, GA/AC and GA/CC genotype was in the low-risk group (Fig. 3). The risk of developing T2DM in the high-risk group was 2.16 times of that in the low-risk group $(\mathrm{OR}=2.165,95 \% \mathrm{CI}=1.478-3.171$, Table 7).
Table 4 Hardy-Weinberg equilibrium test results

\begin{tabular}{|c|c|c|c|c|c|}
\hline \multirow[t]{2}{*}{ Locus } & \multirow[t]{2}{*}{ Genotype } & \multicolumn{2}{|l|}{ Control group } & \multicolumn{2}{|l|}{ T2DM group } \\
\hline & & Observed value & Expected value & Observed value & Expected value \\
\hline \multirow[t]{5}{*}{ rs35749 } & $\mathrm{C} / \mathrm{C}$ & 189 & 194.1 & 579 & 573.9 \\
\hline & $\mathrm{C} / \mathrm{T}$ & 38 & 32.9 & 92 & 97.1 \\
\hline & $\mathrm{T} / \mathrm{T}$ & 2 & 2 & 6 & 6 \\
\hline & $\chi^{2}$ & 0.043 & & 0.121 & \\
\hline & $P$ & 0.979 & & 0.941 & \\
\hline \multirow[t]{5}{*}{ rs 35767} & $\mathrm{G} / \mathrm{G}$ & 120 & 111.7 & 322 & 330.3 \\
\hline & $\mathrm{G} / \mathrm{A}$ & 95 & 96.6 & 287 & 285.4 \\
\hline & $\mathrm{A} / \mathrm{A}$ & 14 & 20.7 & 68 & 61.3 \\
\hline & $\chi^{2}$ & 0.027 & & 0.053 & \\
\hline & $P$ & 0.987 & & 0.974 & \\
\hline \multirow[t]{5}{*}{ rs5742612 } & $\mathrm{A} / \mathrm{A}$ & 167 & 160 & 466 & 473 \\
\hline & $\mathrm{G} / \mathrm{A}$ & 58 & 62.4 & 189 & 184.6 \\
\hline & $\mathrm{G} / \mathrm{G}$ & 4 & 6.6 & 22 & 19.4 \\
\hline & $\chi^{2}$ & 0.083 & & 0.145 & \\
\hline & $P$ & 0.959 & & 0.93 & \\
\hline \multirow[t]{5}{*}{ rs5742694 } & $\mathrm{A} / \mathrm{A}$ & 138 & 145.3 & 437 & 429.7 \\
\hline & $\mathrm{C} / \mathrm{A}$ & 80 & 73.3 & 210 & 216.7 \\
\hline & $\mathrm{C} / \mathrm{C}$ & 11 & 10.4 & 30 & 30.6 \\
\hline & $\chi^{2}$ & 0.021 & & 0.336 & \\
\hline & $P$ & 0.99 & & 0.845 & \\
\hline \multirow[t]{5}{*}{ rs6218 } & A/A & 175 & 166.8 & 49 & 57.1 \\
\hline & $\mathrm{A} / \mathrm{G}$ & 49 & 57.1 & 177 & 168.9 \\
\hline & $\mathrm{G} / \mathrm{G}$ & 5 & 5.1 & 15 & 14.9 \\
\hline & $\chi^{2}$ & 0.038 & & 0.175 & \\
\hline & $P$ & 0.981 & & 0.916 & \\
\hline
\end{tabular}


Table 5 The $I G F-1$ gene polymorphism in the T2DM group and the control group

\begin{tabular}{|c|c|c|c|c|c|}
\hline SNP & Genotype/allele & $\begin{array}{l}\text { Control group } \\
n(\%)\end{array}$ & $\begin{array}{l}\text { T2DM group } \\
n(\%)\end{array}$ & OR $(95 \% \mathrm{CI})$ & $P$ value \\
\hline \multirow[t]{5}{*}{ rs35749 } & $\mathrm{C} / \mathrm{C}$ & $189(82.5)$ & 193 (87.7) & 1.000 & \\
\hline & $\mathrm{C} / \mathrm{T}$ & 38 (16.6) & $26(11.8)$ & $0.67(0.39-1.15)$ & 0.140 \\
\hline & $\mathrm{T} / \mathrm{T}$ & $2(0.9)$ & $1(0.5)$ & $0.49(0.04-5.45)$ & 0.560 \\
\hline & $\mathrm{C}$ & $416(90.8)$ & 412 (93.6) & 1.00 & \\
\hline & $\mathrm{T}$ & $42(9.2)$ & $28(6.4)$ & $0.67(0.41-1.11)$ & 0.120 \\
\hline \multirow[t]{5}{*}{ rs35767 } & $\mathrm{G} / \mathrm{G}$ & $120(52.4)$ & $93(42.3)$ & 1.00 & \\
\hline & $\mathrm{G} / \mathrm{A}$ & 95 (41.5) & $101(45.9)$ & $1.37(0.93-2.03)$ & 0.110 \\
\hline & $\mathrm{A} / \mathrm{A}$ & $14(6.1)$ & $26(11.8)$ & $2.40(1.19-4.84)$ & 0.020 \\
\hline & G & $335(73.1)$ & $287(65.2)$ & 1.00 & \\
\hline & A & 123 (26.9) & $153(34.8)$ & $1.55(1.17-2.06)$ & 0.000 \\
\hline \multirow[t]{5}{*}{ rs5742612 } & $\mathrm{A} / \mathrm{A}$ & $167(72.9)$ & $142(64.5)$ & 1.00 & \\
\hline & $\mathrm{G} / \mathrm{A}$ & $58(25.3)$ & 73 (33.2) & $1.48(0.98-2.23)$ & 0.060 \\
\hline & $\mathrm{G} / \mathrm{G}$ & $4(1.7)$ & $5(2.3)$ & $1.47(0.39-5.58)$ & 0.570 \\
\hline & A & $392(85.6)$ & $357(81.1)$ & 1.00 & \\
\hline & $\mathrm{G}$ & $66(14.4)$ & 83 (18.9) & $1.38(0.97-1.97)$ & 0.070 \\
\hline \multirow[t]{5}{*}{ rs5742694 } & $\mathrm{A} / \mathrm{A}$ & $138(60.3)$ & $150(68.2)$ & 1.00 & \\
\hline & $\mathrm{C} / \mathrm{A}$ & $80(34.9)$ & $59(26.8)$ & $0.68(0.45-1.02)$ & 0.060 \\
\hline & $\mathrm{C} / \mathrm{C}$ & $11(4.8)$ & $11(5.0)$ & $0.92(0.39-2.19)$ & 0.850 \\
\hline & A & $356(77.7)$ & 359 (81.6) & 1.00 & \\
\hline & $\mathrm{C}$ & $102(22.3)$ & $81(18.4)$ & $0.79(0.57-1.09)$ & 0.150 \\
\hline \multirow[t]{5}{*}{ rs6218 } & $\mathrm{A} / \mathrm{A}$ & $175(76.4)$ & $153(69.5)$ & 1.00 & \\
\hline & $\mathrm{A} / \mathrm{G}$ & 49 (21.4) & $65(29.5)$ & $1.52(0.99-2.33)$ & 0.060 \\
\hline & $\mathrm{G} / \mathrm{G}$ & $5(2.2)$ & $2(0.9)$ & $0.46(0.09-2.39)$ & 0.350 \\
\hline & A & $399(87.1)$ & $371(84.3)$ & 1.00 & \\
\hline & $\mathrm{G}$ & 59 (12.9) & 69 (15.7) & $1.26(0.86-1.83)$ & 0.230 \\
\hline
\end{tabular}

\begin{tabular}{llllll}
\hline SNP & Genotype/allele & $\begin{array}{l}\text { Control group } \\
n(\%)\end{array}$ & $\begin{array}{l}\text { T2DM group } \\
n(\%)\end{array}$ & OR (95\%CI) & $P$ value \\
\hline Dominant model & AA+GA & $109(47.6)$ & $127(57.7)$ & 1.00 & \\
& GG & $120(52.4)$ & $93(42.3)$ & $0.665(0.458-0.965)$ & 0.032 \\
Recessive model & AA & $14(6.1)$ & $26(11.8)$ & 1.00 & \\
& GG+GA & $215(93.9)$ & $194(88.2)$ & $0.486(0.247-0.957)$ & 0.034 \\
\hline
\end{tabular}

Table 6 Genetic model of the IGF-1 gene rs 35767 locus in T2DM group and control group

\section{Discussion}

The participants (220 T2DM patients and 229 healthy controls) in this study were recruited from the Uyghur population in Urumqi, Xinjiang, China. The Uyghur residents in Urumqi are mainly from the northern and southern regions of Xinjiang. They are relatively less affected by the Han immigrants, and they have maintained a traditional way of life for generations, with their own language, religious beliefs and marriage custom (Black et al. 2006). Therefore, the Uyghur ethnic group is an ideal population for evaluation of genetic susceptibility and environmental factors. T2DM is a disease caused by genetic and environmental 


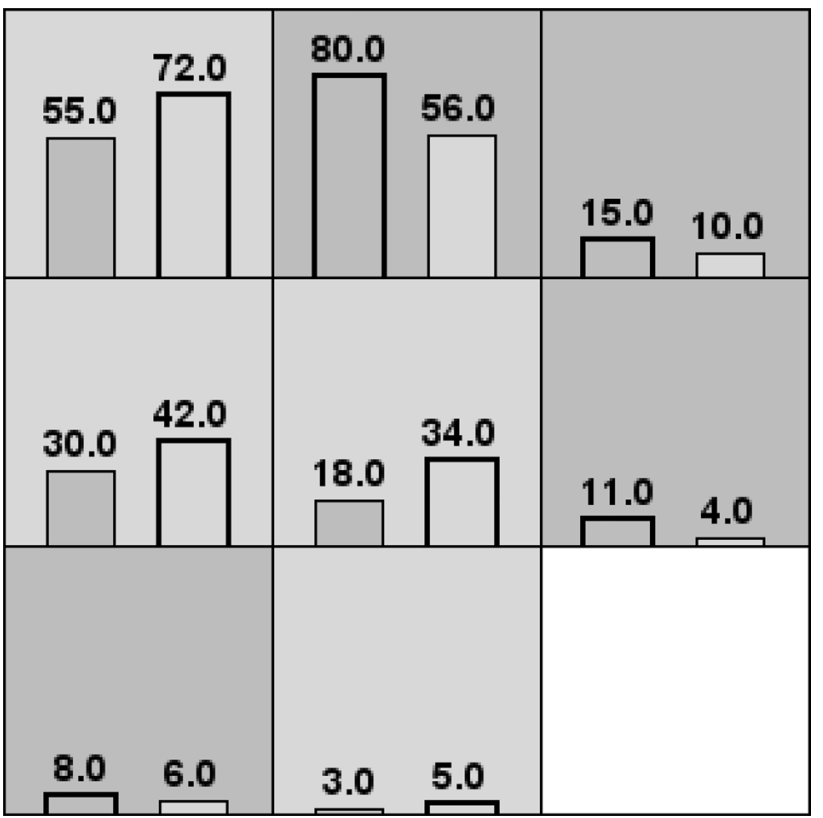

Fig. 3 Distribution of high-risk and low-risk genotypes of interaction between rs35767 and rs5742694. High-risk combinations are represented by dark gray squares, while low-risk combinations are represented by light gray squares

factors ( $\mathrm{Li}$ et al. 2020). Susceptibility to T2DM varies among different ethnic groups. Studying the occurrence and development of T2DM in different ethnic groups is helpful to comprehensively understand the mechanism of this disease. However, there are relatively few studies on the genetic factors of T2DM in Uyghur population.

This study found statistical differences between the levels of TG, TC, HDL, LDL, BUN, and Cr between the T2DM group and the control group. Cohort studies conducted in China, South Korea, the United States and Japan also show that TG is associated with hyperuricemia and diabetes (McAdams-DeMarco et al. 2013; Qiu et al. 2013; Ryu et al. 2012). In T2DM patients, elevated TG, decreased HDL cholesterol, and increased LDL cholesterol are commonly seen (Blanco-Rojo et al. 2017; Zheng et al. 2020). These dyslipidemias may constitute the lipid profile of atherosclerosis and serve as risk factors for T2DM related cardiovascular disease (Howard et al. 2000; Ishikawa et al. 2015; Ye et al. 2019). Therefore, the regulation of dyslipidemias is an effective measure to control T2DM. In addition, it is reported that lower serum $\mathrm{Cr}$ level could increase the risk of T2DM (Larsen et al. 2016). The lifestyle, dietary habits and physical characteristics of the Uyghurs living in Xinjiang are somewhat different from those of the Han. It is shown that the Uyghurs have a high incidence of metabolic diseases (Dong et al. 2017). The Uyghurs' diet is mainly composed pasta, beef and mutton. The intake of fats and dairy foods is significantly higher than the recommended amount in the Chinese Nutritional Dietary Guidelines; whereas the intake of vegetables, beans and fishery products is relatively low, resulting in high total calorie dietary structure and an increase in the overall overweight percentage of Uyghurs (Wang et al. 2013).

A number of studies have shown that excessive fat intake can cause insulin resistance (Kirsten et al. 2017; Bisschop et al. 2001; Wu et al. 2017). Wu et al. (2017) proposed that pancreatic $\beta$-cell dysfunction was a key factor in the development of T2DM. The increase in cholesterol levels in $\beta$-cells caused by the disorder of cholesterol metabolism, the hindrance of glycolysis, the increase of pancreatic $\beta$-cell apoptosis, and the decrease of insulin secretion were considered to be new mechanisms of $\beta$-cell dysfunction. Long-term living in an environment that easily leads to insulin resistance can also easily cause mutations in related genes. IGF-1 is a multifunctional cell growth regulator (Orru et al. 2017). It can be used as an intermediate in the process of insulin deficiency and hyperinsulinemia (Frystyk et al. 2002). Clemmons et al. found that the lack of IGF-1 could lead to more severe insulin resistance (Clemmons 2004). Low levels of IGF-1 can predict impaired glucose tolerance, T2DM, and cardiovascular disease (Dunger et al. 2003). It has been found that compared with other ethnic groups, rs35767 in IGF-1 may be the potential susceptible sites of T2DM in Uygur population (Song et al. $2015 \mathrm{a}, \mathrm{b}$ ). The results of this study also showed that the differences in genotype, allele frequency, dominant and recessive models of IGF-1 gene rs35767 locus between the T2DM group and the control group were statistically significant. Previous study has reported that the effects of the rs35767 polymorphism of IGFI on fasting insulin were mediated by decreased insulin sensitivity or impaired insulin (Mannino et al. 2013). The finding that the
Table 7 The best model of type 2 diabetes-related gene interaction

\begin{tabular}{|c|c|c|c|}
\hline Model & Sample accuracy & $\begin{array}{l}\text { Cross-validation } \\
\text { consistency }\end{array}$ & $P$ value \\
\hline rs35767 & 0.4925 & $7 / 10$ & 0.8281 \\
\hline rs35767×rs5742694 & 0.5863 & $10 / 10$ & 0.0107 \\
\hline rs $35767 \times$ rs5742694 $\times$ rs 6218 & 0.5445 & $9 / 10$ & 0.1719 \\
\hline rs $35749 \times$ rs $35767 \times$ rs $5742694 \times$ rs 6218 & 0.5200 & $10 / 10$ & 0.3770 \\
\hline $\begin{array}{l}\text { rs } 35749 \times \text { rs } 35767 \times \text { rs } 5742612 \times \text { rs } 5742694 \times \\
\text { rs6218 }\end{array}$ & 0.5193 & $10 / 10$ & 0.3770 \\
\hline
\end{tabular}


$\mathrm{G}$ allele of rs35767 (IGF1) is associated with fasting insulin and HOMA-IR in the European population (Dupuis et al 2010) and Han Chinese (Hu et al. 2010) is new.

We used $\mathrm{G}$ as the comparison group, and found that the A allele at rs 35767 was associated with T2DM. Other study also revealed that the $\mathrm{G}$ allele at $\mathrm{rs} 35767$ was associated with reduced fasting insulin levels and insulin resistance $(\mathrm{Hu}$ et al. 2010). However, a meta-analysis of 76,558 non-diabetic populations of European descent found that the $\mathrm{G}$ allele at IGF1 rs35767 was associated with increased fasting insulin levels and insulin resistance (HOMA-IR) (Dupuis et al. 2010). The inconsistent results may be due to the influence of the disease microenvironment, the genotype distribution of different study populations or sample sizes. However, this study is consistent with the report by Manshu et al. (2015), which showed a significant difference in rs35767 (IGF1) G allele frequency between Uygur T2DM patients and control group. Additionally, compared with the control group, the frequency of GG genotype was lower in T2DM patients. These may be related to the dietary habits, living environment, and lifestyle of the Uyghur population discussed earlier. For example, blood glucose metabolism may affect the susceptibility of Uyghurs to diabetes (Zhang 2018). Moreover, the custom of internal marriage of the Uyghurs may also be a reason for the polymorphism of genetic susceptibility (Mamet et al. 2005; Wang et al. 2003).

In 2007, Lou et al. proposed GMDR, a method that can control the interference caused by covariates and improve the prediction accuracy (Lou et al. 2007). To study the interaction of diabetes-related genes, we analyzed the interaction of 5 SNP loci with the GMDR method. The results found that the two-factor model was statistically significant, and the cross-validation was consistent (10/10). The two-factor model contained rs35767 locus and rs5742694 locus, showing a high degree of synergy. Each $\mathrm{G}$ allele in rs35767 has a resistance of HOMA-IR (Hong et al. 2014). Similarly, Mannino et al. also suggested that subjects carrying with the GG genotype of rs35767 showed lower insulin sensitivity and IGF-1 concentration compared with those carrying the A allele (Mannino et al. 2013). The parameters of the rs5742694 polymorphism were reported for the first time as carriers of the TT genotype showing higher insulin sensitivity and lower insulin secretion (Willems et al. 2016). However, no significant correlation was found between the rs5742694 polymorphism and IGF-1 level in serum.

In conclusion, the rs35767 and rs5742694 in $I G F-1$ may be potential susceptibility sites for T2DM in Uygur population. We believe that these findings will provide reference for personalized treatment of T2DM in the future.

Author contributions Study design: TW, JZ; data collection: GT, HS, CC, JZ; statistical analysis: GT, CC, QM; data interpretation: TW; manuscript preparation: TW, GT; literature search: YS, HY; funds collection: TW. All authors reviewed the manuscript.

Funding This study was supported by National Natural Science Foundation of China (grant no. 81660140, 81860179); Teacher's Professional Development Project of Shanghai Municipal Education Commission; and High-Level Local University Construction Projects of Shanghai University of Medicine and Health Sciences.

Data availability The data are available from the corresponding author on reasonable request.

\section{Declarations}

Conflict of interest Tingting Wang, Gulixiati maimaiti tuersun, Haonan Shi, Cheng Chen, Qi Ma, Yinxia Su, Hua Yao and Jia Zhu declare that they have no conflict of interest.

Ethics approval This study was approved by the Ethics Committee of the First Affiliated Hospital of Xinjiang Medical University.

Consent to participate All subjects signed the informed consent.

Consent to publish The authors affirm that human research participants provided informed consent for publication.

Open Access This article is licensed under a Creative Commons Attribution 4.0 International License, which permits use, sharing, adaptation, distribution and reproduction in any medium or format, as long as you give appropriate credit to the original author(s) and the source, provide a link to the Creative Commons licence, and indicate if changes were made. The images or other third party material in this article are included in the article's Creative Commons licence, unless indicated otherwise in a credit line to the material. If material is not included in the article's Creative Commons licence and your intended use is not permitted by statutory regulation or exceeds the permitted use, you will need to obtain permission directly from the copyright holder. To view a copy of this licence, visit http://creativecommons.org/licenses/by/4.0/.

\section{References}

Ahmed SAH, Ansari SA, Mensah-Brown EPK, Emerald BS (2020) The role of DNA methylation in the pathogenesis of type 2 diabetes mellitus. Clin Epigenetics 12:104

Awuti G, Younusi K, Li L, Upur H, Ren J (2012) Epidemiological survey on the prevalence of periodontitis and diabetes mellitus in Uyghur adults from rural Hotan area in Xinjiang. Exp Diabetes Res 2012:758921

Bakhashab S, Filimban N, Altall RM, Nassir R, Qusti SY, Alqahtani MH, Abuzenadah AM, Dallol A (2020) The effect sizes of PPAR $\gamma$ rs1801282, FTO rs9939609, and MC4R rs2229616 variants on type 2 diabetes mellitus risk among the western Saudi population: a cross-sectional prospective study. Genes (basel) 11:98

Bisschop PH, de Metz J, Ackermans MT, Endert E, Pijl H, Kuipers F, Meijer AJ, Sauerwein HP, Romijn JA (2001) Dietary fat content alters insulin- mediated glucose metabolism in healthy men. Am J Clin Nutr 73:554-559

Black ML, Wise CA, Wang W, Bittles AH (2006) Combining genetics and population history in the study of ethnic diversity in the People's Republic of China. Hum Biol 78:277-293 
Blanco-Rojo R, Perez-Martinez P, Lopez-Moreno J, Martinez-Botas J, Delgado-Lista J, van-Ommen B, Yubero-Serrano E, Camargo A, Ordovas JM, Perez-Jimenez F et al (2017) HDL cholesterol efflux normalised to apoA-I is associated with future development of type 2 diabetes: from the CORDIOPREV trial. Sci Rep 7:12499

Clemmons DR (2004) Role of insulin-like growth factor iin maintaining normal glucose homeostasis. Horm Res 62(Suppl 1):77-82

Dong Y, Wang X, Zhang LF (2017) The current status of metabolic syndrome among adults aged 35 years and above in Xinjiang. Chin J Dis Control Prev 21:684-687

Dunger DB, Ong KK, Sandhu MS (2003) Serum insulin-like growth factor-I levels and potential risk of type 2 diabetes. Horm Res 60(Suppl 3):131-135

Dupuis J, Langenberg C, Prokopenko I, Saxena R, Soranzo N, Jackson AU, Wheeler E, Glazer NL, Bouatia-Naji N, Gloyn AL et al (2010) New genetic loci implicated in fasting glucose homeostasis and their impact on type 2 diabetes risk. Nat Genet 42:105-116

Franco L, Williams FM, Trofimov S, Malkin I, Surdulescu G, Spector T, Livshits G (2014) Assessment of age-related changes in heritability and IGF-1 gene effect on circulating IGF-1 levels. Age (dordr) 36:9622

Frystyk J, Ledet T, Moller N, Flyvbjerg A, Orskov H (2002) Cardiovascular disease and insulin-like growth factor I. Circulation 106:893-895

Fujita H, Hara K, Shojima N, Horikoshi M, Iwata M, Hirota Y, Tobe K, Seino S, Kadowaki T (2012) Variations with modest effects have an important role in the genetic background of type 2 diabetes and diabetes-related traits. J Hum Genet 57:776-779

Gong Q, Zhang P, Wang J, Ma J, An Y, Chen Y, Zhang B, Feng X, Li H, Chen X, Cheng YJ, Gregg EW, Hu Y, Bennett PH, Li G; Da Qing Diabetes Prevention Study Group (2019) Morbidity and mortality after lifestyle intervention for people with impaired glucose tolerance: 30 year results of the Da Qing diabetes prevention outcome study. Lancet Diabetes Endocrinol 7:452-461

Hong KW, Chung M, Cho SB (2014) Meta-analysis of genome-wide association study of homeostasis model assessment beta cell function and insulin resistance in an East Asian population and the European results. Mol Genet Genomics 289:1247-1255

Howard BV, Robbins DC, Sievers ML, Lee ET, Rhoades D, Devereux RB, Cowan LD, Gray RS, Welty TK, Go OT et al (2000) LDL cholesterol as a strong predictor of coronary heart disease in diabetic individuals with insulin resistance and low LDL: the strong heart study. Arterioscler Thromb Vasc Biol 20:830-835

Hu C, Jia W (2018) Diabetes in China: epidemiology and genetic risk factors and their clinical utility in personalized medication. Diabetes $67: 3-11$

Hu C, Zhang R, Wang C, Wang J, Ma X, Hou X, Lu J, Yu W, Jiang F, Bao $Y$ et al (2010) Variants from GIPR, TCF7L2, DGKB, MADD, CRY2, GLIS3, PROX1, SLC30A8 and IGF1 are associated with glucose metabolism in the Chinese. PLoS ONE 5:e15542

Ishikawa T, Ayaori M, Uto-Kondo H, Nakajima T, Mutoh M, Ikewaki K (2015) High-density lipoprotein cholesterol efflux capacity as a relevant predictor of atherosclerotic coronary disease. Atherosclerosis 242:318-322

Kodama S, Fujihara K, Ishiguro H, Horikawa C, Ohara N, Yachi Y, Tanaka S, Shimano H, Kato K, Hanyu O et al (2018) Quantitative relationship between cumulative risk alleles based on genomewide association studies and type 2 diabetes mellitus: a systematic review and meta-analysis. J Epidemiol 28:3-18

Kwasniewski W, Gozdzicka-Jozefiak A, Kotarska M, Polak G, Barczynski B, Broniarczyk J, Nowak W, Wolun-Cholewa M, Kwasniewska A, Kotarski J (2015) Analysis of cytosine-adenine repeats in $\mathrm{P} 1$ promoter region of IGF-1 gene in peripheral blood cells and cervical tissue samples of females with cervical intraepithelial lesions and squamous cervical cancer. Mol Med Rep 11:766-774
Larsen BA, Wassel CL, Kritchevsky SB, Strotmeyer ES, Criqui MH, Kanaya AM, Fried LF, Schwartz AV, Harris TB, Ix JH et al (2016) Association of muscle mass, area, and strength with incident diabetes in older adults: the health ABC study. J Clin Endocrinol Metab 101:1847-1855

Li XS, Yan CY, Fan YJ, Yang JL, Zhao SX (2020) NUCB2 polymorphisms are associated with an increased risk for type 2 diabetes in the Chinese population. Ann Transl Med 8:290

Lou XY, Chen GB, Yan L, Ma JZ, Zhu J, Elston RC, Li MD (2007) A generalized combinatorial approach for detecting gene-bygene and gene-by-environment interactions with application to nicotine dependence. Am J Hum Genet 80:1125-1137

Mamet R, Jacobson CK, Heaton TB (2005) Ethnic intermarriage in Beijing and Xinjiang, China, 1990. J Comp Fam Stud 36:187

Mancuso E, Mannino GC, Fatta CD, Fuoco A, Spiga R, Andreozzi F, Sesti G (2017) Insulin-like growth factor-1 is a negative modulator of glucagon secretion. Oncotarget 8:51719-51732

Mannino GC, Greco A, De Lorenzo C, Andreozzi F, Marini MA, Perticone F, Sesti G (2013) A fasting insulin-raising allele at IGF1 locus is associated with circulating levels of IGF-1 and insulin sensitivity. PLoS ONE 8:e85483

McAdams-DeMarco MA, Law A, Maynard JW, Coresh J, Baer AN (2013) Risk factors for incident hyperuricemia during midadulthood in African American and white men and women enrolled in the ARIC cohort study. BMC Musculoskelet Disord 14:347

Orru S, Nigro E, Mandola A, Alfieri A, Buono P, Daniele A, Mancini A, Imperlini E (2017) A functional interplay between IGF-1 and adiponectin. Int J Mol Sci 18:2145

Qin L, Zhao J, Wu Y, Zhao Y, Chen C, Xu M, Cheng J, Li C (2019) Association between insulin-like growth factor 1 gene rs 35767 polymorphisms and cancer risk: a meta-analysis. Medicine (baltimore) 98:e18017

Qiu L, Cheng XQ, Wu J, Liu JT, Xu T, Ding HT, Liu YH, Ge ZM, Wang YJ, Han HJ et al (2013) Prevalence of hyperuricemia and its related risk factors in healthy adults from Northern and Northeastern Chinese provinces. BMC Public Health 13:664

Ryu S, Chang Y, Zhang Y, Kim SG, Cho J, Son HJ, Shin H, Guallar E (2012) A cohort study of hyperuricemia in middle-aged South Korean men. Am J Epidemiol 175:133-143

Sarega N, Imam MU, Esa NM, Zawawi N, Ismail M (2016) Effects of phenolic-rich extracts of Clinacanthus nutans on high fat and high cholesterol diet-induced insulin resistance. BMC Complement Altern Med 16:88

Song M, Zhao F, Ran L et al (2015a) The Uyghur population and genetic susceptibility to type 2 diabetes: potential role for variants in CDKAL1, JAZF1, and IGF1 Genes. OMICS J Integr Biol 19:230-238

Song M, Zhao F, Ran L, Dolikun M, Wu L, Ge S, Dong H, Gao Q, Zhai Y, Zhang L et al (2015b) The Uyghur population and genetic susceptibility to type 2 diabetes: potential role for variants in CDKAL1, JAZF1, and IGF1 genes. OMICS 19:230-237

Tao Y, Mao X, Xie Z, Ran X, Liu X, Wang Y, Luo X, Hu M, Gen $\mathrm{W}$, Zhang $\mathrm{M}$ et al (2008) The prevalence of type 2 diabetes and hypertension in Uygur and Kazak populations. Cardiovasc Toxicol $8: 155-159$

Wang W, Wise C, Baric T, Black ML, Bittles AH (2003) The origins and genetic structure of three co-resident Chinese Muslim populations: the Salar, Bo' an and Dongxiang. Hum Genet 113:244-252

Willems SM, Cornes BK, Brody JA, Morrison AC, Lipovich L, Dauriz M, Chen Y, Liu CT, Rybin DV, Gibbs RA et al (2016) Association of the IGF1 gene with fasting insulin levels. Eur J Hum Genet 24:1337-1343

Xing DG, Zhang DY, Wang ZF, Ding DL, Wang J, Wang YJ (2014) Correlations of ANP genetic polymorphisms and serum levels 
with ischemic stroke risk: a meta-analysis. Genet Test Mol Biomarkers 18:349-356

Yakar S, Rosen CJ, Beamer WG, Ackert-Bicknell CL, Wu Y, Liu JL, Ooi GT, Setser J, Frystyk J, Boisclair YR et al (2002) Circulating levels of IGF-1 directly regulate bone growth and density. J Clin Invest 110:771-781

Ye X, Kong W, Zafar MI, Chen LL (2019) Serum triglycerides as a risk factor for cardiovascular diseases in type 2 diabetes mellitus: a systematic review and meta-analysis of prospective studies. Cardiovasc Diabetol 18:48

Zhang YY (2018) A case-control study of the association between dietary pattern and type 2 diabetes with Uygur in Urumqi. Xinjiang Medical University, Urumqi
Zheng D, Li H, Ai F, Sun F, Singh M, Cao X, Jiang J, He Y, Tang Z, Guo X (2020) Association between the triglyceride to highdensity lipoprotein cholesterol ratio and the risk of type 2 diabetes mellitus among Chinese elderly: the Beijing longitudinal study of aging. BMJ Open Diabetes Res Care 8:e000811

Publisher's Note Springer Nature remains neutral with regard to jurisdictional claims in published maps and institutional affiliations.

\section{Authors and Affiliations}

\section{Tingting Wang ${ }^{1} \cdot$ Gulixiati Maimaitituersun $^{2} \cdot$ Haonan $\mathrm{Shi}^{2} \cdot$ Cheng $\mathrm{Chen}^{3} \cdot \mathrm{Qi} \mathrm{Ma}^{4} \cdot \mathrm{Yinxia} \mathrm{Su}^{2,5} \cdot \mathrm{Hua} \mathrm{Yao}^{2,5}$. Jia Zhu ${ }^{6}$}

1 School of Nursing and Health Management, Shanghai University of Medicine and Health Sciences, Shanghai 201318, China

2 School of Public Health, Xinjiang Medical University, Urumqi 830054, China

3 Clinical Laboratory Center, People's Hospital of Xinjiang Uygur Autonomous Region, Urumqi 830001, China

4 Xinjiang Key Laboratory of Metabolic Disease, Clinical Medical Research Institute, The First Affiliated Hospital of Xinjiang Medical University, No.137. Liyushan road, Xinshi District, Urumqi 830001, China

5 Health Management Institute, Xinjiang Medical University, Urumqi 830054, China

6 Cadre Health Center, People's Hospital of Xinjiang Uygur Autonomous Region, No. 91, Tianchi Road, Tianshan District, Urumqi 830001, China 